\title{
A Fatigue Strength Prediction Model for Surface Roughness and Nitriding Effectson SAE 1035 Steel
}

\author{
O.O Obiukwu",O.M.I. Nwafor, B.Okafor, G.O.Osueke \\ Department of Mechanical Engineering, School Of Engineering and Engineering Technology, Federal \\ University of Technology, Owerri, Imo State, Nigeria.
}

*Corresponding Author: O.O Obiukwu, Department of Mechanical Engineering, School Of Engineering and Engineering Technology, Federal University of Technology, Owerri, Imo State, Nigeria.

\begin{abstract}
The effects of surface roughness and nitriding treatment on fatigue failure of SAE1035 steel were investigated. After nitriding heat treatments, the fatigue strength of the various specimen having different finishes further improved. For the three average surface roughness $(\mathrm{Ra})$ considered, three equations which describe the $S-N$ curves were established. The application of these equations to specimens tested under cumulative fatigue damage shows that the roughness parameter must not be ignored. Hence a model considering this parameter is formulated. From the model, the fatigue strength predictions were in good agreement with the experimental results.
\end{abstract}

Keywords: Fatigue strength prediction; surface roughness; SAE 1035 carbon steel; nitriding.

\section{INTRODUCTION}

Fatigue is an important parameter in studying the behaviour of materials subjected to constant and variable amplitude loading [1]. These material which are regularly subjected to cyclic loading are prone to fatigue damage, which often start at the surface due to localized stress concentrations caused by machining marks, exposed inclusions or the contrasting movement of dislocations. Fatigue prediction is an important way to improve service performance and control failure particularly where safety is paramount. Components of machines, vehicles and structures are frequently subjected to cyclic loads, which in some cases may lead to their failure due to fatigue [2]. According to Bannantine et al. [3] fatigue failure involves a multi-stage processes that begins with crack initiation, followed by a progressive crack growth across the part with continued cyclic loading, and finally the sudden fracture of the component or specimen. Crack initiation and propagation, in most cases, can be attributed to surface integrity produced by machining [4]. Fatemi and Yang [2] reported that there are three commonly recognized forms of fatigue namely; high cycle fatigue (HCF), low cycle fatigue (LCF) and thermal mechanical fatigue (TMF). The average surface roughness (Ra) value might vary from 0.2 microns for a good polish to 8 microns for a rough turned finish [5]. Fatigue cracks initiate predominantly at the free surface of a material, and the condition of the surface can be assumed to be critical with regard to fatigue crack initiation [6]. Since the surface finish of the materials can be controlled during machining, it is often considered by manufacturers in order to increase the life of the products [7]. Various kinds of surface effects can be of great importance to the fatigue life. Surface effects include all conditions capable of reducing or enhancing the crack initiation period [8]. Bayoumi [9] studied the effect of surface finish on fatigue strength. Surface roughness of each group of specimens was measured and the quality of surface evaluated from the profile graph. Low-cycle fatigue tests subject specimens to repeated stress or strain until failure occurs at a relatively small number of cycles [10]. The upper limit in low-cycle life has generally been selected arbitrarily by individual investigators to lie in the range of $10^{2}$ to $10^{5}$ cycles. A study on effect of low cycle fatigue on surface finish was conducted by Kuroda and Marrow [11]. Nitriding is a thermo chemical surface treatment in which nitrogen is transferred from an ammonia atmosphere into the surface of steels at temperatures within the ferrite and carbide phase region $[12,13]$. The fatigue life prediction of components have drawn more interests in many fields, in recent times. Reliable life prediction method 
is an important way to improve service performances and control failure accidents. The surface roughness and heat treatment are important factors affecting the fatigue life [18-22].

\section{Experimental Procedures}

SAE 1035medium carbon steel was selected as a material of study. Standard fatigue specimens were prepared according to Avery Dennison machine 7305 Fatigue Testing standards. From the material used, hour-glass shaped specimens were turned to shape with surface roughness of $\mathrm{Ra} \approx 1.58 \mu \mathrm{m}$. These conditions were selected from the response surface to obtain surface finish that were close the average roughness required [14]. The population of specimens with this surface roughness is later referred as series F. Three additional series were created out of series F. Another one was grinded $(\mathrm{G})$ to an average surface roughness of $\mathrm{Ra} 1.38$ (series $\mathrm{G}$ ). Series $\mathrm{T}$ were lathe turned with Ra 0.86 . The last series $(\mathrm{P})$ were polished with Ra value of 0.32 . Surface roughness of the specimens was measured using Surface Roughness Tester (TR100). The stair case method was used in applying the moment. The applied bending moment was increased by a fixed increment and the next specimen was tested with the new bending moment.

The fatigue test of the material in air was done for the as received materials (SAE 1035 Steel). The bending moments imposed were 681.7, 1022.6, 1363.5, 1704, and 2045KN-m for the various Surface finish. The bending test was performed at a frequency of $50 \mathrm{~Hz}(1400 \mathrm{rpm})$ for each specimen. This was a complete reversed cycle of stress range and is equal to minimum stress divided by maximum stress which is equal to a negative value (-1) in fatigue tests. Nitriding is a surface-hardening heat treatment that introduces nitrogen into the surface of steel at a temperature range $\left(500\right.$ to $\left.550^{\circ} \mathrm{C}\right)$, while it is in the ferritic condition. The samples were heated in an atmosphere of hydrocarbon mixed with Ammonia $\left(\mathrm{NH}_{3}\right)$. It was then cooled in the atmosphere. Because nitriding does not involve heating into the austenite phase and a subsequent quench to form martensite, nitriding was accomplished with a minimum of distortion and with excellent dimensional control.

\subsection{Mathematical Models Development}

The test model programme was divided into the following three groups:

Polished Group 1 with mean average roughness of $(\mathrm{Ra}=0.32 \mu \mathrm{m})$. Five specimens were tested at low cycle fatigue to obtain fatigue data at constant amplitude loading and zero mean stress.

Grinded Group 2 with mean average roughness of $(\mathrm{Ra}=0.86 \mu \mathrm{m})$. Five specimens were tested in this group.

Lathe Turned Group 3 with mean average roughness of $(\mathrm{Ra}=1.58 \mu \mathrm{m})$. Five specimens of average roughness $1.58 \mu \mathrm{m}$ were. The $\mathrm{S}-\mathrm{N}$ curve equation for the data was formulated as follows (using the least square method in MATLAB computer simulation):Nitrided

Polished:

$\sigma=23840 \mathrm{~N}_{\mathrm{f}}^{-0.3010}$

(Grinded:)The S-N curve equation which describes the results in the table is:

$\sigma=23240 \mathrm{~N}_{\mathrm{f}}^{-0.4508}$

(Turned:) The S-N curve equation of the results can be written as:

$\sigma=17310 \mathrm{~N}_{\mathrm{f}}^{-0.3195}$

Table 1gives the life prediction of specimens according to equations (1, 2 and 3).Knowing that the stress value used in these equations is the average value of the variable applied stresses equations $(1-3)$.

Table1. The life prediction of specimens according to equations $(1,2,3)$

\begin{tabular}{|c|c|c|c|c|c|}
\hline $\begin{array}{l}\text { Stress } \\
\left(\mathrm{N} / \mathrm{mm}^{2}\right)\end{array}$ & $\begin{array}{c}\mathrm{N}_{\mathrm{f}} \text { (based on } \\
\text { eq.1) }\end{array}$ & $\mathrm{N}_{\mathrm{f}}$ (eq.2) & $\mathrm{Ks}$ & $\mathrm{N}_{\mathrm{f}}$ (eq.3) & $\mathrm{Ks}$ \\
\hline 681.7 & 3568.16 & 4581.14 & 1.28 & 1408.95 & 0.395 \\
\hline 1022.6 & 969.9 & 1177.56 & 1.21 & 548.3 & 0.57 \\
\hline 1363.5 & 384.9 & 449.1 & 1.17 & 280.7 & 0.73 \\
\hline 1704 & 188.1 & 212.8 & 1.13 & 167.1 & 0.89 \\
\hline 2045 & 104.7 & 115.52 & 1.10 & 109.3 & 1.04 \\
\hline
\end{tabular}


Surface roughness factor (Ks) is defined by the following [15]

$\mathrm{Ks}=\frac{N_{f}(\text { for actual speciman })}{N_{f}(\text { for roug h,polis hed })}$

It is clear from Table 2 that the value of Ks (smooth surface) equals unity while Ks (medium surface) equals to (0.89) and Ks (rough surface) equals to (0.395).

Table2. Surface roughness factor $(K s)$,

\begin{tabular}{|l|l|l|l|l|l|l|}
\hline $\begin{array}{l}\text { Specimen } \\
\text { No. }\end{array}$ & Ra $\mu \mathrm{m}$ & $\begin{array}{l}\text { Kc(based on } \\
\text { Equ(1) }\end{array}$ & Kc (2) & Kc(3) & Kc (4) & $\operatorname{Kc}(5)$ \\
\hline E1 & $(0.32 \mu \mathrm{m})$ & 5.23 & 1.42 & $(0.56)$ & 0.17 & 0.15 \\
\hline E2 & $(0.86 \mu \mathrm{m})$ & 4.48 & 1.15 & $(0.44)$ & 0.21 & 0.11 \\
\hline E3 & $(1.38 \mu \mathrm{m})$ & 1.03 & 0.40 & $(0.21)$ & 0.12 & 0.08 \\
\hline E4 & $(0.32 \mu \mathrm{m})$ & 2.26 & $(0.88)$ & 0.45 & 0.27 & 0.18 \\
\hline
\end{tabular}

Correction factor $(\mathrm{Kc})$ is calculated from the comparison between the experimental and predicted life of each specimen, Table 3 [16].

$K c=\frac{N_{f} \text { experimental }}{N_{f} \text { predicted }}$

\section{RESULTS AND DISCUSSION}

\subsection{Effect of Surface Finish on Fatigue Strength}

Figure 1 shows S-N Curve for nitrided samples. As evident in this figure, there is a notable difference in fatigue strength amongst the specimens, although high plastic deformation and the machined surface finish continued to contribute to fatigue damage accumulation. The rate of damage and the corresponding contribution of surface finish to fatigue failure of the medium carbon steel specimens with larger roughness were faster in the case of grinded specimen. Nitriding has the combined effect of producing a higher strength material on the surface as well as causing volumetric changes which produce residual compressive surface stresses. After the nitriding treatment, a compound layer and an underlying diffusion zone (case) were formed at the surface of the medium carbon steel. The compound layer, also known as the white layer, consists predominantly of $\mathrm{Fe}_{4} \mathrm{~N}$ as nitrogen has partial solubility in iron. In the region beneath the compound layer, that is the case, for pure iron, nitrogen from outside dissolves interstitially in the ferrite lattice at the nitriding temperature. The hardened diffusion case is responsible for a considerable enhancement of the fatigue endurance.

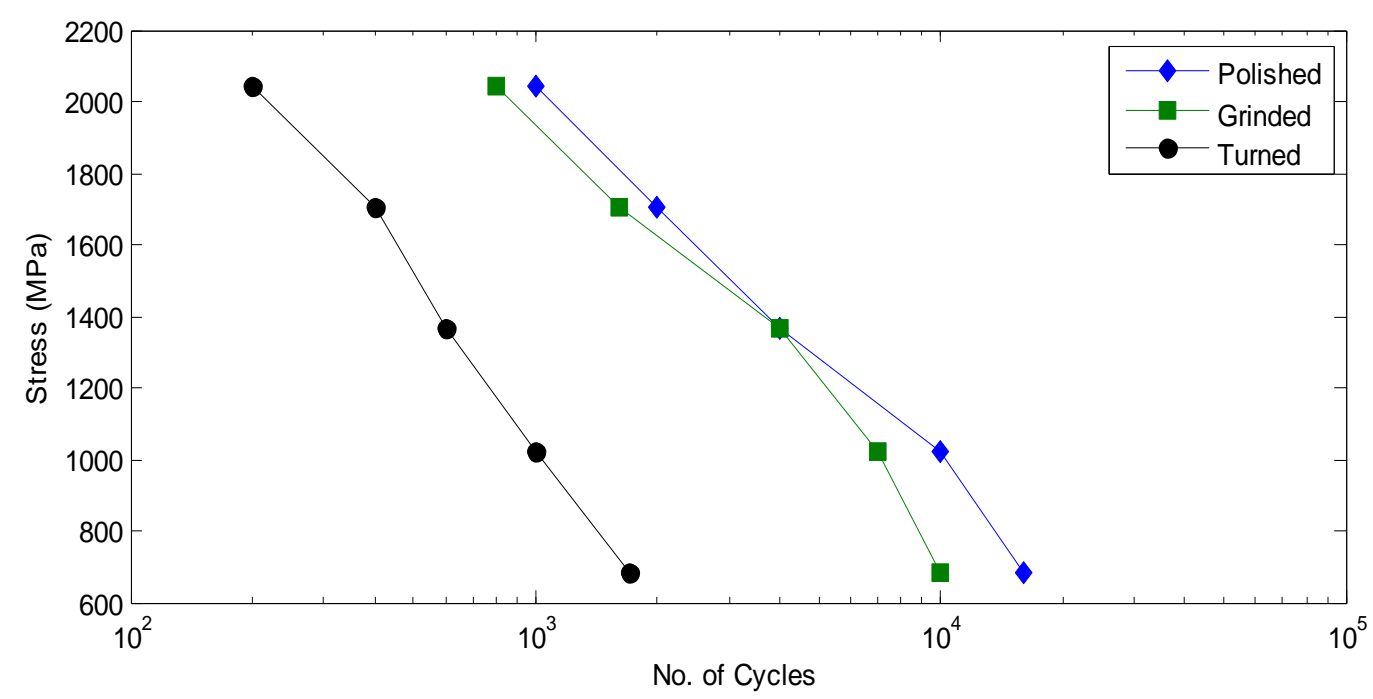

Figure1. S-N Curve for Nitrided samples

\subsection{Hardness Test}

Hardness values for the samples are shown in figure2 (a).Hardness test results show the variation with respect to both surface finish and the different heat treatment conditions. These are results which interpret the difference in heat-treatment types and it also helps to understand the mechanism behind the property alteration. Mechanical properties are enhanced as the materials passed through the heat 
treatment processes. In this research, specimens corresponding to all carburized heat-treatment temperatures showed higher hardness as compared to the nitrided specimens of the same steel. From the figure, it is observed that the polished and nitrided specimens are softer than that of the turned and grinded heat-treated samples. The rougher samples attained higher surface nitride concentration and revealed greater hardness gain. The lathe turned (nitrided) samples, where the measured surface roughness $(R a=1.38)$ was larger than those of the other samples provided a greater number of sites available for nitride molecules deposition. This, in turn, increased the density of adsorbed nitride atoms and enhanced nitride diffusion flux from the steel surface to the bulk of the material. As a result it has higher hardness value of $321 \mathrm{HBR}$ as compared to the polished (nitrided) samples having hardness value of $170 \mathrm{HBR}$.

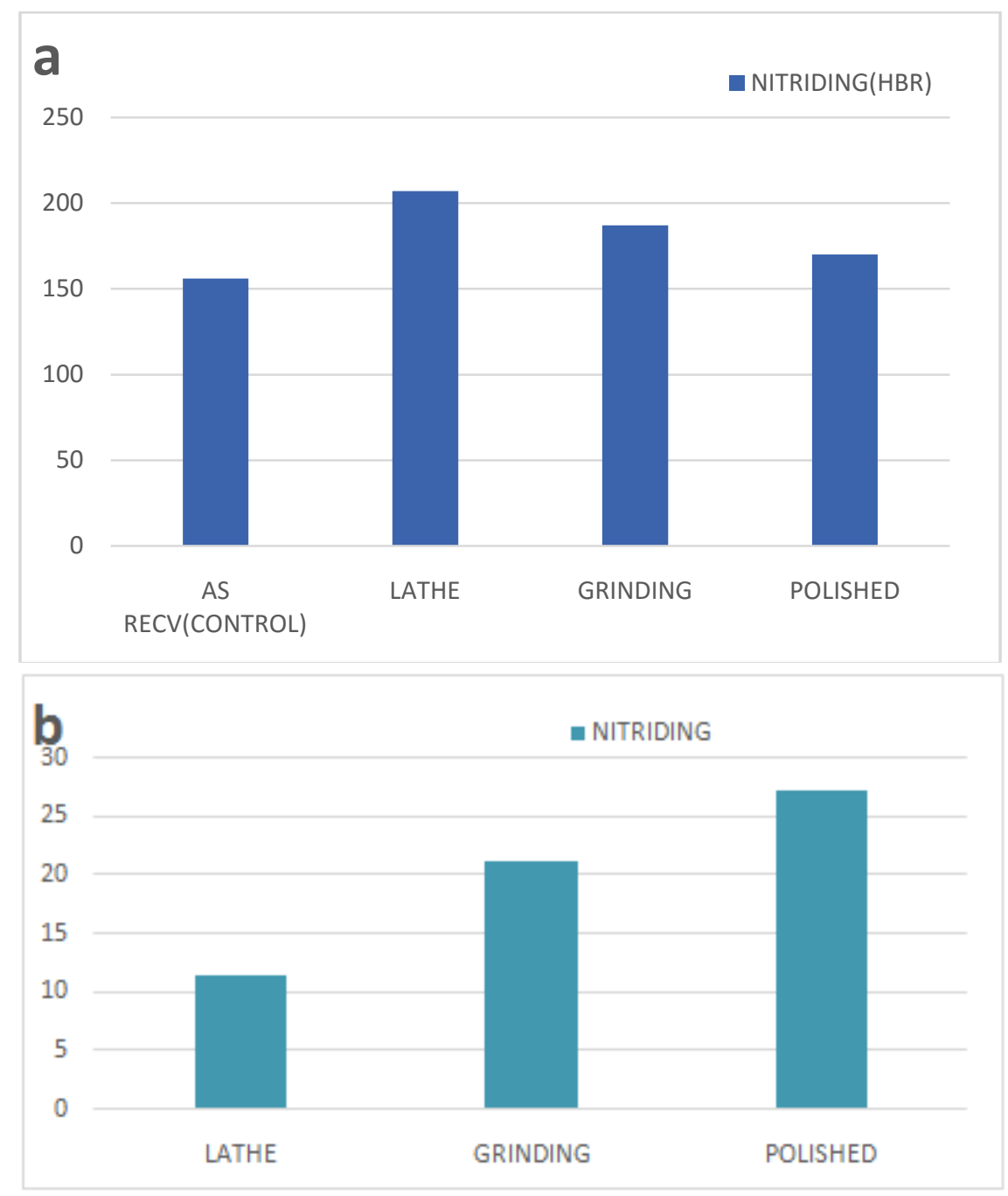

Figure 2. (a) Hardness of surface finished and heat treated specimens, (b) Impact test of surface finished and heat treated specimens

\subsection{Impact Test}

Figure 2 (b) shows the impact test results. Due to the refinement of the case and the core of the medium carbon steel sample with the heat treatments, it was observed that the polished and nitrided sample has the highest toughness followed by grinding leaving the lathe turned with the least energy/ resistance to fracture.

\subsection{Proposal of a Model for Predicting Fatigue Life}

The S-N curve equation for the data was formulated (using the least square method in MATLAB computer simulation):

Generally an increase in surface roughness is accompanied by a decrease in fatigue strength and in fatigue life. [17] Also it is clear that, from table 3, for high surface roughness (rough surface) Kc is 
about 0.21 based on equation 3 while this value becomes 0.44 based on equation 2 and 0.56 based on equation 1 .

Table 3. The values Kc of cumulative fatigue specimen tests.

\begin{tabular}{|c|c|c|c|c|c|c|}
\hline & Specimen No. & $\begin{array}{c}(\mathrm{A}) \\
\mathrm{N}_{\mathrm{f}} \\
\text { predicted } \\
\text { Cycles }\end{array}$ & $\begin{array}{c}(\mathrm{B}) \\
\mathrm{N}_{\mathrm{f}} \\
\text { predicted } \\
\text { Cycles }\end{array}$ & $\begin{array}{c}(\mathrm{C}) \\
\mathrm{N}_{\mathrm{f}} \text { predicted } \\
\text { Cycles }\end{array}$ & $\begin{array}{c}(\mathrm{D}) \\
\mathrm{N}_{\mathrm{f}} \text { predicted } \\
\text { Cycles }\end{array}$ & $\begin{array}{c}\text { ( E ) } \\
\mathrm{N}_{\mathrm{f}} \text { predicted } \\
\text { Cycles }\end{array}$ \\
\hline $\begin{array}{c}\text { As } \\
\text { Received }\end{array}$ & $\mathrm{E} 1(0.32 \mu \mathrm{m})$ & 3568.16 & 969.9 & $(384.9)$ & 188.1 & 104.7 \\
\hline & $\mathrm{E} 2(0.86 \mu \mathrm{m})$ & 4581.14 & 1177.56 & $(449.1)$ & 212.8 & 115.52 \\
\hline & $\mathrm{E} 3(1.38 \mu \mathrm{m})$ & 1408.95 & 548.3 & $(280.7)$ & 167.1 & 109.3 \\
\hline & $\mathrm{E} 7(0.32 \mu \mathrm{m})$ & 134466.6 & $(34956.1)$ & 13440.3 & 6408.65 & 3495.94 \\
\hline Nitrided & $\mathrm{E} 8(0.86 \mu \mathrm{m})$ & $(2510.9)$ & 1021.3 & 539.5 & 329 & 219.53 \\
\hline & $\mathrm{E} 9(1.38 \mu \mathrm{m})$ & 24921.2 & 7004.16 & 2846.3 & 1416.6 & $(800.38)$ \\
\hline
\end{tabular}

This difference in Ks values is due to the difference in surface roughness value (Ra). In order to avoid the large error in life prediction and to make Kc about unity, it is necessary to take into account the roughness $(\mathrm{Ra})$ especially when the difference in $(\mathrm{Ra})$ value is big. A new model is developed which takes into account the difference in $(\mathrm{Ra})$ values. This model is written as:

As Received, $\sigma_{f}=10837\left(R_{a}\right)^{-0.17} N_{f}^{-0.3705}$

Nitrided, $\sigma_{f}=21463\left(R_{a}\right)^{-0.24} N_{f}^{-0.38515}$

The above equationsare developed based on experimental data of the groups 1,2 and 3. Using the least square method in MATLAB software. Figures 3 shows the predicted number of cycles to failure using equation (6 and 7).

(a)

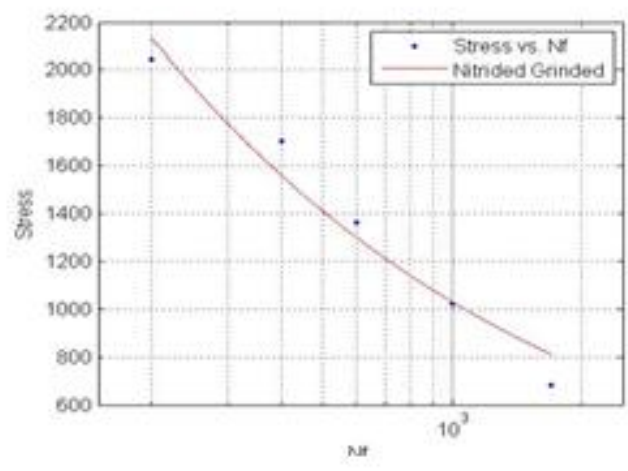

(b)

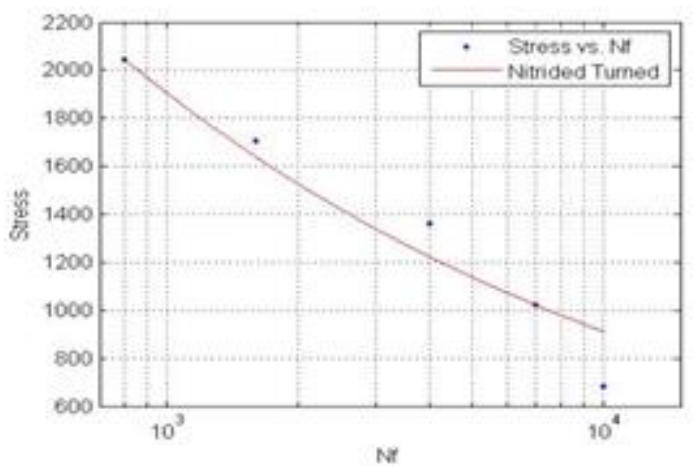

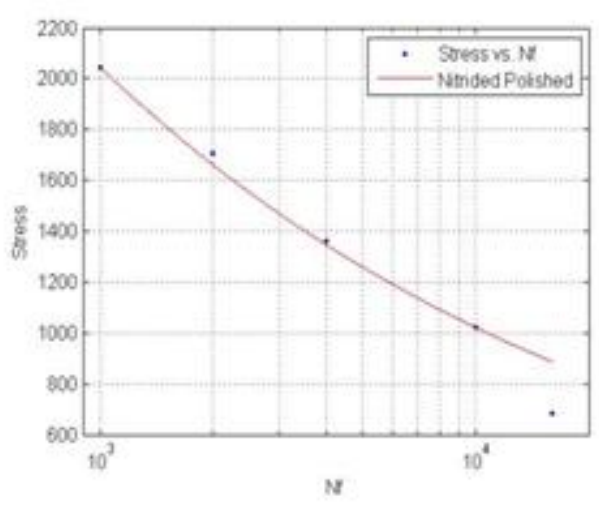

(c)

Figure 3. (a) model generated for nitrided Grinded, $\sigma=23240 N_{f}^{-0.4508}$, (b) model generated for nitride Turned, $\sigma=17310 \mathrm{~N}_{f}^{-0.3195}$, (c) model generated nitride Polished, $\sigma=23840^{\text {Nf-0.3010 }}$

A comparison between the predicted number of cycles to failure and the experimental result is shown 
in figure 4.It is clear that when using equations 6 and 7,the life predictions are in good agreement with the experimental life. Therefore Equations 6 and 7 validates the experimental results.

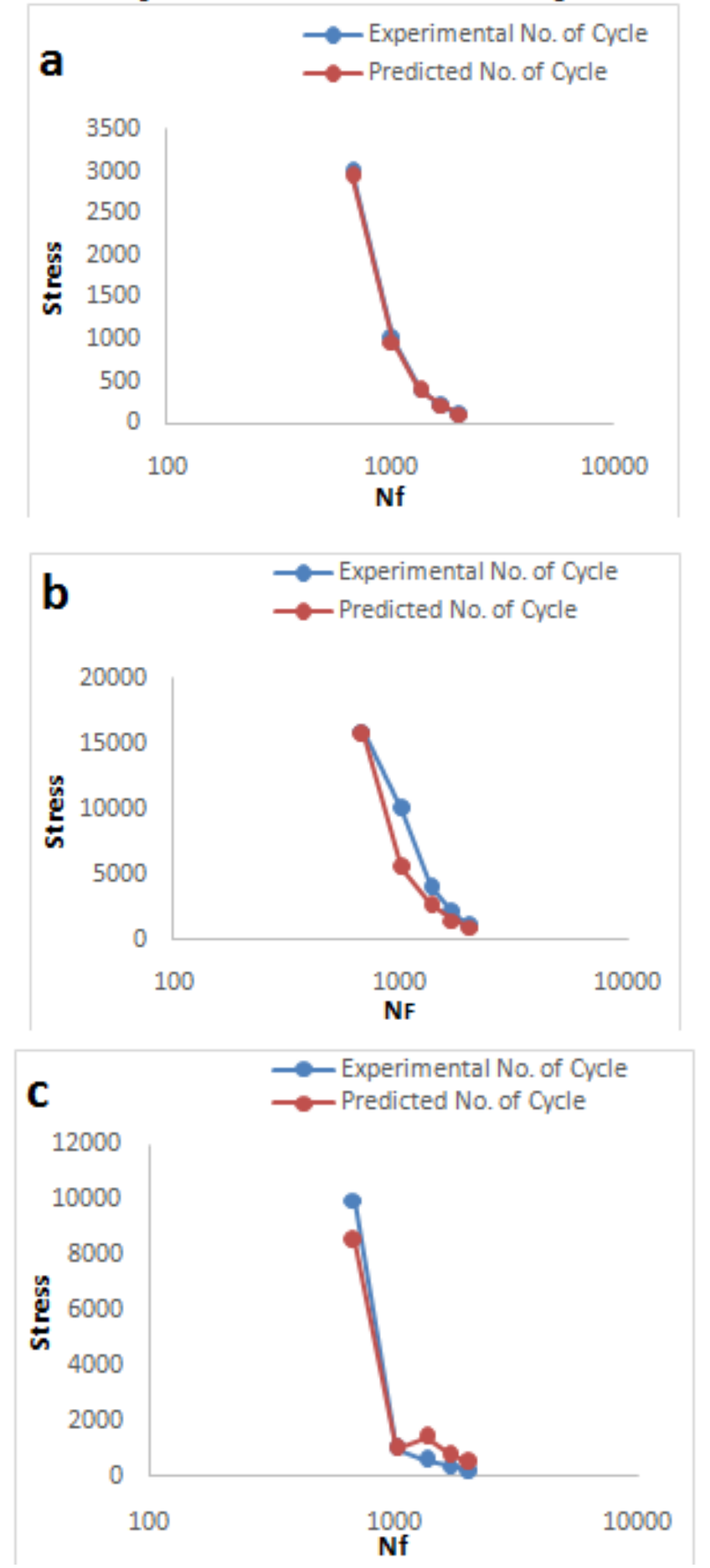

Figure4. Comparison of Experimental and Predicted number of cycles $\left(N_{f}\right)$ for $(a)$ Polished As received, (b) Polished Nitrided, (c) Grinded Nitrided

\section{CONCLuSion}

Tests to determine the mechanical properties of SAE 1035 steel in the as-received condition revealed that the SAE 1035 had a hardness of $156 \mathrm{HB}$ as compared with a brinell hardness of $207 \mathrm{HB}$ for nitrided specimens lathe turned respectively. It is concluded that the differences in hardness levels are largely responsible for the differences shown in the S-N curves. The impact properties indicated that the nitrided specimens had the highest toughness/ resistance to fracture compared to the as-received specimens. The S-N curves for completely reversed bending were first established for the material tested in the as-received condition. S-N curves were drawn to examine the effect of machined surface quality (surface finish) on the fatigue life of the medium carbon steel specimens with varying surface 
roughness. The bending strength was plotted against the Number of cycles to failure. It was observed that the fatigue life increased as the bending load on the specimen decreased. It was also found that the surface with lower surface roughness (polished specimen; $\mathrm{Ra}=0.32 \mu \mathrm{m}$ ) has better fatigue life. The lathe turned surface with higher roughness (turned; $\mathrm{Ra}=1.58 \mu \mathrm{m}$ ) however showed relatively lower fatigue life. Thus, it is concluded that polished surface increases the fatigue life of machined components when compared to grinded and lathe turned specimens. This is because rough surfaces form stress concentration centers, thus leading to decreasing endurance limit. Results on nitrided specimens illustrate the dependence of the fatigue behavior on case hardening process control and microstructure. It was shown that significant gains in the fatigue performance of case-hardened medium carbon steels was realized through nitriding heat treatment. The best results were obtained for the polished specimen nitrided with lower surface roughness $(R a=0.32 \mu \mathrm{m})$. These specimens have also shown the highest endurance limit. This is perhaps, due to the fact that after heat treatment these specimens possessed very high strength with significant ductility. The results show that, polishing and nitriding are the best surface finish and heat treatment options respectively. It is therefore concluded that the specimen having higher compressive residual stresses built up bear higher endurance limits. Roughness of the surface is important factor and must be taken into consideration for prediction of fatigue life. The application of the developed models to the fatigue specimens validated the experimental results. A new life prediction model is derived from this study which includes the effect of difference roughness and nitriding treatment values. This model is formulated as $\sigma_{f}=21463\left(R_{a}\right)^{-0.24} N_{f}^{-0.38515}$

\section{ACKNOWLEDGEMENT}

The authors would like to thank Mr. AloIreti for his assistance with the fatigue, heat treatments, and Mechanical properties tests.

\section{REFERENCES}

[1] Torres, M.A.S., Voorwald, H.J.C., (2002). An evaluation of shot peening, residual stress and stress relaxation on the fatigue life of AISI 4340 steel. Int. J. Fatigue, 24(8):877-886. [doi:10.1016/S01421123(01)00205-5]

[2] Fatemi A. and Yang L., 1998," Cumulative Fatigue Damage and Life Prediction Theories: a Survey of the State of The Art for Homogeneous Material", International Journal of Fatigue, vol. 20, pp 9-34.

[3] Bannantine, J.A., Comer, J.J. and Handrock, J.L. (1990), Fundamentals of metal fatigue analysis, Prentice Hall, New York.

[4] Zahavi E and Torbilo V.( 1996) Fatigue design - life expectancy of machine

[5] Gunnberg F, Escursell M, Jacobson M. (2006) The influence of cutting parameters on residual stresses and surface topography during hard turning of $18 \mathrm{MnCr} 5$ case carburised steel. $\mathrm{J}$ Mater ProcTechnol2006;174:82-90.

[6] Sasahara H. (2005)The effect on fatigue life of residual stress and surface hardness resulting from different cutting conditions of $0.45 \% \mathrm{C}$ steel. J Mach Tool Manuf;45:131-6.

[7] Javidi A., Rieger U. and Eichlseder W. (2008) The effect of machining on the surface integrity and fatigue life., International Journal of Fatigue, Vol. 30, Issues 10-11, Pages 2050-2055,

[8] Schijve J. (2001), Fatigue of Structures and Materials, Netherland: Kluwer Academic Publiser.

[9] Bayoumi M.R. and Abdellatif A. K (1995): Effect of Surface Finish on Fatigue Strength, Engineering Fracture Mechanics Vol. 51, No. 5, p 861-870

[10] M. Kuroda, T.J. Marrow (2007) Modeling the effects of surface finish on fatigue limit in austenitic stainless steels, Fatigue FractEngng Mater Struct. 31 1-18.

[11] M. Kuroda, T.J. Marrow (2008) Preparation of Fatigue specimens With Controlled Surface Characteristics, Journal of Materials Processing Tech, 203, 396-403.

[12] Ashrafizadeh, F. (2003). Influence of plasma and gas nitriding on fatigue resistance of plain carbon (Ck45) steel, Surface and Coatings Technology, 173(174), 1196-1200.

[13] Suh, C.M., Hwang, J.K., Son, K.S., \&Jangb, H.K. (2005). Fatigue characteristics of nitride SACM 645 according to the nitriding condition and notch, Materials Science and Engineering, 392, $31-37$.

[14] Murakami Y. (2002). Effect of surface roughness on fatigue strength, Metal Fatigue: Effect of Small Defects and Non Metallic Inclusions, 28-40, Elsevier, Kidlington, Oxford, UK.

[15] Khairallah S. J. (2011) Surface Roughness Effect on Fatigue Life Preditions under Cumulative Damage Eng. And Tech. Journal, Vol. 29, No. 6. 
[16] M. Suraratchai, J. Limido, C. Mabru, R. Chieragatti, "Modelling the Influence of Machined Surface Roughness on the Fatigue Life of Aluminium Alloy", Journal of Fatigue to be Published (2011).

[17] Sadayoshi Chiaki and Yasumitsu Tomita, "A Fatigue Strength Prediction Model for Steel-Resin Cocured Jointed Interfaces with Roughness", Proceeding of the Tenth (2000) International Offshore and Polar Engineering Conference seattle, USA, May 28-June, (2000).

[18] Arola D, Williams CL. Estimating the fatigue stress concentration factor of machined surfaces. Int $\mathbf{J}$ Fatigue 2002;24(9):923-930.

[19] Ås SK, Skallerud B, Tveiten BW, Holme B. Fatigue life prediction of machined components using finite element analysis of surface topography. Int J Fatigue. 2005;27(10):1590-1596.

[20] Beretta S, Ghidini A, Lombardo F. Fracture mechanics and scale effects in the fatigue of railway axles. EngFract Mech. 2005;72(2):195-208.

[21] Furuya Y. Size effects in gigacycle fatigue of high-strength steel under ultrasonic fatigue testing. Procedia Eng. 2010;2(1):485-490.

[22] Sun C, Zhang X, Liu X, Hong Y. Effects of specimen size on fatigue life of metallic materials in high-cycle and very-highcyclefatigue regimes. Fatigue FractEng Mater Struct. 2016;39(6):770-779.

Citation: O.O Obiukwu, et.al, (2020)" A Fatigue Strength Prediction Model for Surface Roughness and Nitriding Effectson SAE 1035 Steel”, International Journal of Modern Studies in Mechanical Engineering, 6(1), pp. 1-8. DOI: http://dx.doi. org/10.20431/2454-9711.0601001

Copyright: (C) 2020 Authors, This is an open-access article distributed under the terms of the Creative Commons Attribution License, which permits unrestricted use, distribution, and reproduction in any medium, provided the original author and source are credited. 